Lepr Rev (1986) 57, Supplement 3, 265-271

\title{
Efficacy of different regimens in multibacillary leprosy
}

\author{
S R PATTYN \\ University of Antwerp, Institute for Tropical Medicine, National- \\ straat 155, 2000 Antwerp, Belgium
}

The necessity for combined chemotherapy in multibacillary leprosy has been recognized for about 15 years. ${ }^{1-3}$ It was however entirely unknown how this combined therapy had to be applied, particularly in respect to the drugs to be given, the frequency of their administration and above all the duration of therapy.

We have approached the problem on the basis of results obtained in experimental chemotherapy of Mycobacterium leprae infections in mice, ${ }^{4-12}$ observations made in $\operatorname{man}^{13-15}$ and prospective chemotherapeutic trials in patients. ${ }^{16-19}$

From studies in mice and man, we know that there are at present two bactericidal drugs: rifampicin (RMP) and the thioamides (either ethio- or prothionamide, ETH or PRO), and two mainly bacteriostatic drugs: dapsone (DDS) and clofazimine (CLO). RMP is extremely bactericidal, killing about 5 logs of $M$. leprae af ter a single dose of $1500 \mathrm{mg}$ or a few doses of $600 \mathrm{mg}$. Due to its profound effect on $M$. leprae, it can also be given intermittently up to once a month $^{8}$ whereas ETH or PRO when administered less than three times a week, are inactive. ${ }^{9,10}$

Dapsone and clofazimine are interchangeable as bacteriostatic drugs, and since they have a different action mechanism they do not show cross-resistance.

From what was known in the treatment of tuberculosis, we concluded that what was needed for the treatment of MB leprosy was ${ }^{1,2}$ an association of two and preferably three, bactericidal drugs (but only two are available in leprosy) in order to obtain maximal killing of $M$. leprae; and the addition of a bacteriostatic drug, whose main role would be to prevent the selection of organisms resistant to the bactericidal drugs.

In this interpretation of the events occurring during chemotherapy, the use of a second bacteriostatic drug was unnecessary. We therefore used in all our trials DDS in new patients and replaced it by CLO in patients at risk for secondary DDS-resistance, defined as those patients who had been treated with DDS for 5 
years or more. (The importance of primary DDS resistance was unknown when we started our studies.)

We accepted as an unproven premise, that daily administration of RMP had a greater bactericidal effect than intermittent administration. Although we had found that, with the Morphological Index as a measure, there was no difference between daily 600 and weekly $900 \mathrm{mg}$ of $\mathrm{RMP}^{16}$ and with relapse as a measure $\mathrm{r}^{15}$ two doses of $600 \mathrm{mg}$ RMP per week were sufficient. Thus it was clear that in the association ETH-RMP, the latter could be given intermittently but with what intervals remained to be investigated.

As a conservative measure the first regimens studied contained daily administration of the combination RMP-ETH. In later trials RMP was given intermittently after an introductory phase of daily RMP.

The question of the duration of therapy has many facets. A particular aspect to be fully realized in the treatment of leprosy, is the dissociation between bacterial killing and skin smear status: M. leprae can be rapidly killed by appropriate bactericidal drugs but the dead bacilli are extremely slowly eliminated by the host. This means that the Bacterial Index cannot be used as a measure of cure - only the eventual appearance of relapse is a reliable criterion.

Thus the question concerning the moment of appearance of relapses becomes crucial, since this will define the duration of the follow-up period af ter the end of treatment and will influence greatly the timescale for prospective treatment trials. Our observations showed that $50 \%$ of relapses in MB disease appear within 2 years and $50 \%$ of relapses in PB leprosy within 3 years after the end of therapy. ${ }^{20,21}$ We thus proceeded on the premises that antibacterial treatment can be stopped in the presence of a positive BI, and that the measure for cure is the absence of relapse, being documented by congruent clinical, bacteriological (MI!) histopathological information, together with the result of mouse footpad inoculation of bacteria from a skin biopsy.

The duration of treatment can only be defined by trial and error. We decided to proceed stepwise downward from 1 year. This 1-year period was not entirely arbitrary: in the treatment of tuberculosis, regimens comprising two bactericidals were highly effective when applied during 9-12 months.

The following 12 month regimens were tested in Burundi and on the island of Anjouan, Republic of the Comores ${ }^{17}$ :

$$
\text { 8-44 RED }
$$

8W RMP $6007 / 7+44$ W RMP $6001 / 7$

52W ETH $5007 / 7$

52W DDS $1007 / 7$

\section{8-44 REC}

8W RMP $6007 / 7+44$ W RMP 600 1/7

52W ETH $5007 / 7$

52W CLO $1007 / 7$ 
The REC regimen was given to patients at risk of or with proven secondary DDS resistance. ${ }^{23}$ The results are presented in Table 1. It may be concluded from these results that MB leprosy can be cured by a treatment regimen of 1-year duration. However these regimens are difficult to apply on a large scale. It was therefore decided to start another trial in which the supervised treatment was reduced to 6 months. In Zaire and Rwanda the following regimens were applied:

$\mathrm{RED} / \mathrm{ED}$ or RED/D

26W RMP $6007 / 7 \mid$ + 26 W ETH 500 7/7, DDS 100 7/7

ETH $5007 / 7$ or (randomization)

DDS $1007 / 7$ + 26 W ETH $5007 / 7$, CLO $1007 / 7$

or $\mathrm{REC} / \mathrm{EC}$ or $\mathrm{REC} / \mathrm{C}$

26W RMP $6007 / 7$ + 26 W ETH 500 7/7; CLO 100 7/7

ETH $5007 / 7$ or (randomization)

CLO $1007 / 7$ +26W CLO $1007 / 7$

Regimen RED was administered to all newly diagnosed male patients and all male patients treated previously for less than 5 years. They were randomized between RED/ED and RED/D. Regimen REC was administered to all female patients and all male patients treated previously for 5 years or more. They were randomized between regimens $\mathrm{REC} / \mathrm{EC}$ and $\mathrm{REC} / \mathrm{C}$.

The results are presented in Table 2 , and the confidence limits for the different groups and regimens in Table 3.

The results of this study show that it is possible to cure MB leprosy by a

Table 1. Follow-up of multibacillary patients in Anjouan and Burundi

\begin{tabular}{lccc}
\hline & $\begin{array}{c}\text { Previously } \\
\text { untreated }\end{array}$ & $\begin{array}{c}\text { Previously } \\
\text { treated }\end{array}$ & $\begin{array}{c}\text { Previously treated } \\
\text { and DDS-R }\end{array}$ \\
\hline & $8-44$ RED & $8-44$ RED & $8-44$ REC \\
\hline Total & 98 & 59 & 21 \\
Died & 3 & 2 & 1 \\
Lost & 4 & - & 3 \\
& 91 & 57 & 17 \\
$2 \mathrm{yr}$ & 89 & 54 & 17 \\
$3 \mathrm{yr}$ & $23 / 25(\times)$ & $25 / 28$ & $4 / 4$ \\
\hline
\end{tabular}

Number of patients with 3 year follow-up/number of patients taken in. Upper $95 \%$ confidence limits for absence of relapses after 2 and 3 years. RED in new patients: $0 / 89=4.0 \%$ RED in new and old patients: $0 / 143=2 \cdot 50 \%$. Overall $0 / 160=2 \cdot 28 \%$ 
Table 2. Number of patients in each category and treatment groups and their follow-up.

\begin{tabular}{|c|c|c|c|c|c|c|c|c|}
\hline & \multicolumn{4}{|c|}{$\mathrm{NC}$} & \multicolumn{4}{|c|}{ OC } \\
\hline & RED/D & $\mathrm{RED} / \mathrm{ED}$ & $\mathrm{REC} / \mathrm{C}$ & $\mathrm{REC} / \mathrm{EC}$ & RED/D & RED/ED & $\mathrm{REC} / \mathrm{C}$ & $\mathrm{REC} / \mathrm{EC}$ \\
\hline Total & 27 & 37 & 22 & 11 & 10 & 6 & 67 & 62 \\
\hline Lost & 3 & 8 & 4 & 2 & 2 & - & 7 & 4 \\
\hline Excl. & - & 1 & 1 & - & - & - & 3 & 2 \\
\hline \multirow[t]{2}{*}{ Died } & - & 4 & - & - & 1 & 1 & 5 & 12 \\
\hline & 24 & 24 & 17 & 9 & 7 & 5 & 51 & 44 \\
\hline $2 \mathrm{yr}$ & 23 & 15 & 14 & 6 & $6(+1)$ & 4 & 44 & 36 \\
\hline $3 \mathrm{yr}^{*}$ & $6 / 11$ & $3 / 6$ & $4 / 6$ & $2 / 2$ & $3 / 3$ & $2 / 2$ & $19 / 25$ & $15 / 21$ \\
\hline
\end{tabular}

NC, new cases; OC, old cases.

Excluded, treatment stopped because of toxic hepatitis.

Yr, years after the end of therapy.

* Numerator: number of patients seen at 3 years after the end of treatment, denominator: number of patients taken in the study during 1981 .

$(+1), 1 \mathrm{pt}$ not seen at 2 years, was so at 3 years

Table 3. Upper $95 \%$ confidence limits for the different treatment regimens of MB leprosy at 2 years after the end of treatment.

\begin{tabular}{|c|c|c|c|c|}
\hline a. RED/D & $\mathrm{NC}$ & $0 / 23$ & & $14.8 \%$ \\
\hline b. REC/C & $\mathrm{NC}$ & $0 / 14$ & & \\
\hline c. RED/ED & $\mathrm{NC}$ & $0 / 15$ & & \\
\hline d. REC/EC & $\mathrm{NC}$ & $0 / 9$ & & \\
\hline e. RED/D & $\mathrm{OC}$ & $0 / 7$ & & \\
\hline f. $\mathrm{REC} / \mathrm{C}$ & $\mathrm{OC}$ & $0 / 44$ & & $8.0 \%$ \\
\hline g. RED/ED & $\mathrm{OC}$ & $0 / 4$ & & \\
\hline h. REC/EC & $\mathrm{OC}$ & $0 / 36$ & & $9 \cdot 7 \%$ \\
\hline Total & & $0 / 152$ & $=$ & $2 \cdot 4 \%$ \\
\hline$+\mathrm{b}:$ & & $0 / 37$ & $=$ & $9 \cdot 4 \%$ \\
\hline & & $0 / 24$ & $=$ & $14 \cdot 2 \%$ \\
\hline$+f:$ & & $0 / 51$ & $=$ & $6 \cdot 2 \%$ \\
\hline T11. & & $0 / 40$ & $=$ & $8 \cdot 8 \%$ \\
\hline$+b+c+d$ & & $0 / 61$ & $=$ & $5 \cdot 8 \%$ \\
\hline
\end{tabular}


treatment regimen of 1-year duration, during which rifampicin is given during the first 6 months only. Since RMP is the main bactericidal, and since there is no difference between the administration of DDS or CLO with and without ETH during the second semester, it seems that ETH has little effect. The necessity of any additional treatment after 6 months of a powerful bactericidal combination may even be questioned.

Therefore a regimen of 6 months duration was tested. Such a regimen was applied in Istanbul in collaboration with T. Saylan et al. ${ }^{19}$

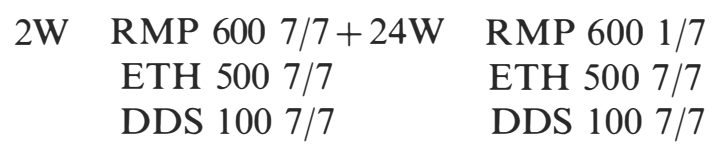

(With DDS replaced by CLO in patients treated for 5 years or more with DDS).

Unfortunately only a small number of patients could be followed for 2 years after the end of treatment, widening the confidence limit to $11.9 \%$.

The above regimens were also accompanied by a serious and unforeseen complication, namely toxic hepatitis due to the association RMP-ETH. It occurs in $3 \cdot 5-5 \%$ of patients, after 5-186 days of treatment, with a mean of 93 days and a median of 76 days, whether the combination RMP-ETH is given daily throughout or only during an introductory phase of $2-8$ weeks.

In the meantime results of a still shorter drug regimen of 3 months duration have become available. The regimen is:

13W RMP $6002 / 7$

ETH $5007 / 7$

DDS $1007 / 7$ (or CLO $1007 / 7$ )

Sixty-four patients were taken into the trial. From each of them $5 \cdot 10^{3}$ bacilli from the skin were inoculated into mouse footpads in Antwerp to ascertain the viability of the organisms.

Bacilli from 33 patients proved infectious for mice. These patients were all bacteriologically positive at the end of therapy. Biopsies from patients have again been inoculated into mouse footpads at 2 years follow-up. No viable bacilli could be detected. The patients have been followed for the third year, none of them has shown any sign of relapse. Furthermore, not a single case of hepatitis has been observed. This may be the result of several concurrent factors:

1 Considerable shortening of the duration of treatment: whereas toxic hepatitis manifests after a median treatment duration of 93 days, a 90-day regimen should eliminate $50 \%$ of hepatitis cases.

2 RMP is administered intermittently twice a week from the very start of treatment.

3 The small number of patients in this study (39). However a total of 61 were 
Table 4. Comparison of four treatment regimens in multibacillary leprosy

\begin{tabular}{|c|c|c|c|c|c|c|}
\hline \multirow[b]{2}{*}{ Regimens } & & \multicolumn{2}{|c|}{ Duration in weeks } & \multirow{2}{*}{$\begin{array}{l}\text { Doses } \\
\text { of RMP }\end{array}$} & \multirow{2}{*}{$\begin{array}{c}\text { Number of } \\
\text { new patients }\end{array}$} & \multirow[b]{2}{*}{$\mathrm{CI} \dagger$} \\
\hline & & treatment & RMP administration & & & \\
\hline 8-44 RED(C) & $\begin{array}{r}8 w 6 / 7 \\
44 w 1 / 7\end{array}$ & 52 & 52 & 92 & 89 & $4 \%$ \\
\hline $\begin{array}{r}\mathrm{RED} / \mathrm{D}(\mathrm{E}) \\
\mathrm{C}(\mathrm{E})\end{array}$ & $\begin{array}{l}26 w 6 / 7 \\
26 w 6 / 7\end{array}$ & 52 & 26 & 156 & 48 & $7 \cdot 4 \%$ \\
\hline $\begin{array}{l}\text { 2E7D7 } \\
\text { 24R1E7D7 }\end{array}$ & & 26 & 26 & 36 & 23 & $12 \%$ \\
\hline 13R2E7D7 & & 13 & 13 & 26 & $33^{*}$ & $10 \cdot 6 \%$ \\
\hline
\end{tabular}

* Patients whose bacilli in the skin were infections for mouse footpads

$\dagger \mathrm{CI}$, upper $95 \%$ confidence interval.

included, 22 of them with negative mouse footpad results, and not included in the final analysis of the results of the antibacterial treatment.

In conclusion MB leprosy can be cured by regimens of 12, 6 and even 3 months duration.

Table 4 shows the confidence limits of the results obtained in relation to the number of doses of RMP administered and the duration of therapy. Daily administration of RMP is not a necessity thus invalidating one of our starting premises. Depending on the regimens, twice or even once weekly administrations are sufficient, thus improving also on the toxicity.

It seems that as in experimental chemotherapy in the mouse there is a relationship between the dosage of RMP, the intermittency and the duration of treatment, allowing for widely different regimens in terms of the total dose of RMP administered and the duration of treatment. Thus regimens could be devised that are adapted to widely different local situations.

\section{References}

${ }^{1}$ Pattyn SR. Comments on the chemotherapy of leprosy as influenced by the present knowledge on Mycobacterium leprae. Lepr Rev, 1972; 43: 126-136.

2 Pattyn SR. The strategy of leprosy treatment: a personal view. Ann Soc Belge Med Trop, 1980; 60: 253-262.

3 WHO Expert Committee on Leprosy (1970). Fourth Report Geneva. Technical Report Series 459.

4 Shepard CC. Minimal effective dosages in mice of clofazimine and of ethionamide against Mycobacterium leprae. Proc Soc Exp Biol Med, 1969; 132: 120- 124.

${ }_{5}^{5}$ Shepard CC. Combination of drugs against Mycobacterium leprae, studied in mice. Int J Lepr, 1972; 40: 33-39. 
${ }^{6}$ Shepard CC. Experimental chemotherapy in leprosy, then and now. Int J Lepr, 1973; 41: $307-$ 319.

7 Ellard GA. Growing points in leprosy research. Recent advances in the chemotherapy of leprosy. Lepr Rev, 1974; 45: 31-40.

${ }^{8}$ Pattyn SR, Saerens EJ. Results of intermittent treatment with dapsone and rifampicin in mice inoculated with Mycobacterium leprae. Ann Soc Belge Med Trop, 1974; 54: 35-41.

${ }_{9}$ Pattyn SR. Further data on the effect of ethionamide and prothionamide in experimental leprosy. Lepr Rev, 1978; 49: 199-202.

${ }^{10}$ Colston MJ, Ellard GA, Gammon PT. Drugs for combined therapy: experimental studies on the antileprosy activity of ethionamide and prothionamide and general review. Lepr Rev, 1978; 49: $115-126$.

${ }^{11}$ Pattyn SR, Van Loo G. Combined chemotherapy against Mycobacterium leprae in the mouse. Ann Soc Belge Med Trop, 1980; 60: 291-295.

12 Pattyn SR, Portaels F, Van Loo, Van den Breen L. Activity of the combination of isoniazid, prothionamide and dapsone against Mycobacterium leprae and some other mycobacteria. Drug Res, 1981; 31: 2155-2157.

${ }^{13}$ Shepard CC, Levy L, Fasal P. Rapid bactericidal effect of rifampin on Mycobacterium leprae. Am J Trop Med Hyg, 1972; 21: 446-449.

14 Shepard CC, Levy L, Fasal P. Further experience with the rapid bactericidal effect of rifampin on Mycobacterium leprae. Am J Trop Med Hyg, 1974; 23: 1120-1124.

15 Pattyn SR, Saint André P, Ferracci C, Baquillon G. Comparative study of two regimens of combined therapy of one year duration in multibacillary leprosy. Int Lepr, 1984; 52: 297-303.

16 Pattyn SR, Rollier MT, Rollier R, Saerens EJ, Dockx P. A controlled clinical trial on initial three months continuous and intermittent rifampicin therapy in lepromatous leprosy. Lepr Rev, 1975; 46: 129-139.

17 Pattyn SR, Bourland J, Grillone S. Combined regimens of one year duration in the treatment of multibacillary leprosy. I. Combined regimen with rifampicin administered during one year. 1986. In press.

18 Pattyn SR, Janssens L, Deverchin J, Groenen G. Combined regimens of one year duration in the treatment of multibacillary leprosy. II. Combined regimens with rifampicin administered during 6 months. 1986. In press.

19 Onsun N, Saylan T, Pattyn SR. Combined chemotherapy of multibacillary leprosy of 6 months duration. 1986. In press.

${ }^{20}$ Nollet E, Janssens L, Groenen G, Bourland J, Pattyn SR. Incubation time for relapse in multibacillary leprosy. Int $J$ Lepr, 1984; 52: 686.

${ }^{21}$ Pattyn SR. Incubation times of relapses after treatment of paucibacillary leprosy. Lepr Rev, 1984; 55: 115-120.

22 Bourland J, Van Loo L, Pattyn SR. Dapsone resistant leprosy in Burundi. Lepr Rev, 1983; 54: 239-242. 